\title{
Atropisomeric Dyes: Axial Chirality in Orthogonal BODIPY Oligomers
}

\author{
Safacan Kolemen, ${ }^{\dagger, \S}$ Yusuf Cakmak, ${ }^{\dagger, \S}$ Ziya Kostereli, ${ }^{\ddagger}$ and Engin U. Akkaya ${ }^{*}, \dagger$ \\ ${ }^{\dagger}$ UNAM-National Nanotechnology Research Center, Bilkent University, Ankara, 06800, Turkey \\ ${ }^{\ddagger}$ Department of Chemistry, Bilkent University, Ankara, 06800, Turkey
}

\section{Supporting Information}

ABSTRACT: A dissymmetrically substituted orthogonal BODIPY dimer and an orthogonal BODIPY trimer exist as two stable conformers, which are in fact atropisomeric enantiomers. The racemic mixture can be separated by HPLC using a chiral stationary phase. These enantiomeric derivatives hold great potential as chiral agents in asymmetric synthesis, fluorogenic/chromogenic sensing, and biological applications.

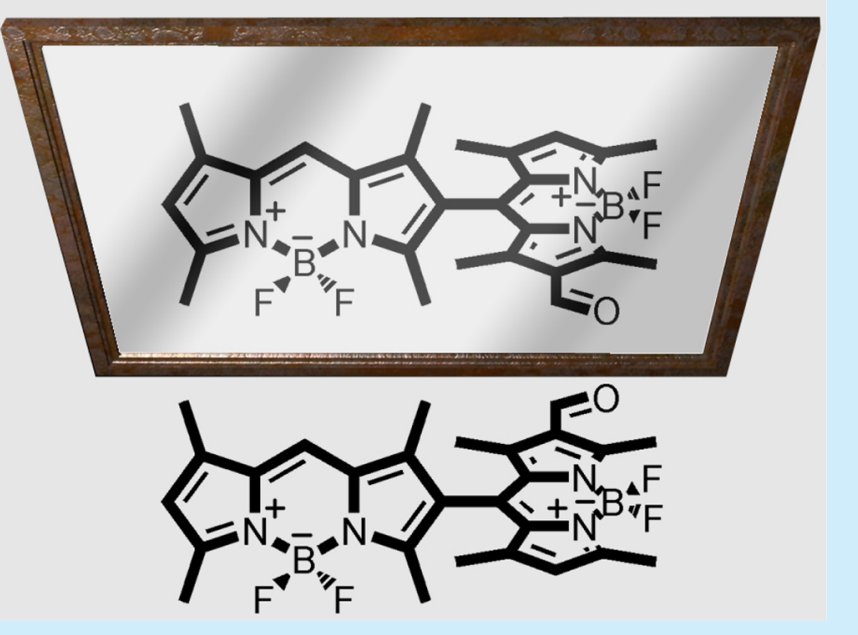

B ODIPY dyes, once considered to be yet another class of fluorophores with applications limited to laser dyes and biological labeling, continue to flourish as their rich chemistry ${ }^{1}$ unravels and a multitude of new potential applications keep pouring in. ${ }^{2}$ It is remarkable that all positions on the parent boradiazaindacene ring including the boron bridge can be functionalized using straightforward procedures, resulting in a large family of chromophores with an impressive diversity of photophysical and photochemical properties. Case in point, the parent compound has a very small intersystem crossing rate, ${ }^{3}$ but on heavy atom functionalization of the 3,5-positions, BODIPY derivatives are transformed into effective singlet oxygen generators with potential in photodynamic therapy. 4

In our attempts to find an alternative to the heavy atom substitution protocol, we discovered that orthogonal BODIPY dimers have a remarkable excited state feature, which makes them very efficient in intersystem crossing. ${ }^{5}$

The dimer (3, Scheme 1) is locked at a particular conformation due to a double methyl-methyl clash, and both single crystal X-ray diffraction studies (Figure 1) and computational studies ${ }^{5}$ confirmed this particular structure.

At that point, we recognized the potential of this compound for atropisomerism. Axial chirality in atropisomeric compounds is the result of a nonplanar arrangement of different groups on both sides of the chiral plane, and enantiopure products can be isolated because of the restricted rotation of a single bond on that chiral axis. Most extensively used and studied atropisomeric molecules are binaphthyl derivatives with various applications. ${ }^{6}$ On the other hand, chiral BODIPY derivatives were also previously reported; ${ }^{7}$ in a few, chirality is generated by the tethered chiral prosthetic groups, ${ }^{7}$ and in one recent example, it is generated by the asymmetrically substituted boron bridge. ${ }^{8}$ Nevertheless, chirality based on rotationally hindered BODIPY cores was not previously proposed or explored.

In the case of dimer 3 , there is still a symmetry plane; however, a single dissymmetric substitution would remove that. To carry out that operation chemically, we formylated dimer 3. The reaction takes place essentially exclusively in the mesofunctionalized ring. To further increase the complexity, we wanted to generate another BODIPY unit, where the formyl carbon would then supply the meso-carbon for the nascent third BODIPY ring. The latter reaction was carried out following highly established procedures for BODIPY synthesis while the pyrrole rings were supplied by 2,4-dimethylpyrrole (Scheme 1). It should be also noted here that the formyl group is a highly useful precursor for other functionalities. For both the formyl derivative 4 and the trimer 5, purification (as the racemic mixture) was through silica gel chromatography using dichloromethane/methanol (95\%/5\%) and only dichloromethane as the eluent solvents, respectively. The racemates were then subjected to chiral HPLC purification. The conditions had to be carefully optimized to affect efficient separation of both enantiomeric couples.

Received: November 5, 2013

Published: January 13, 2014 
Scheme 1. Synthesis of the Atropisomeric BODIPY Derivative 4 and $5^{a}$

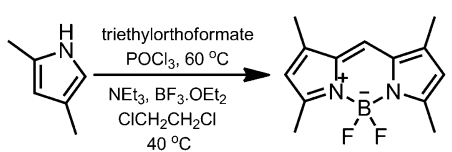

(1)

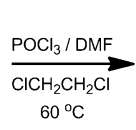

$(95 \%)$

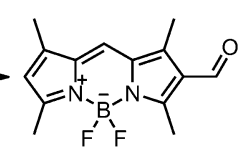

(2)

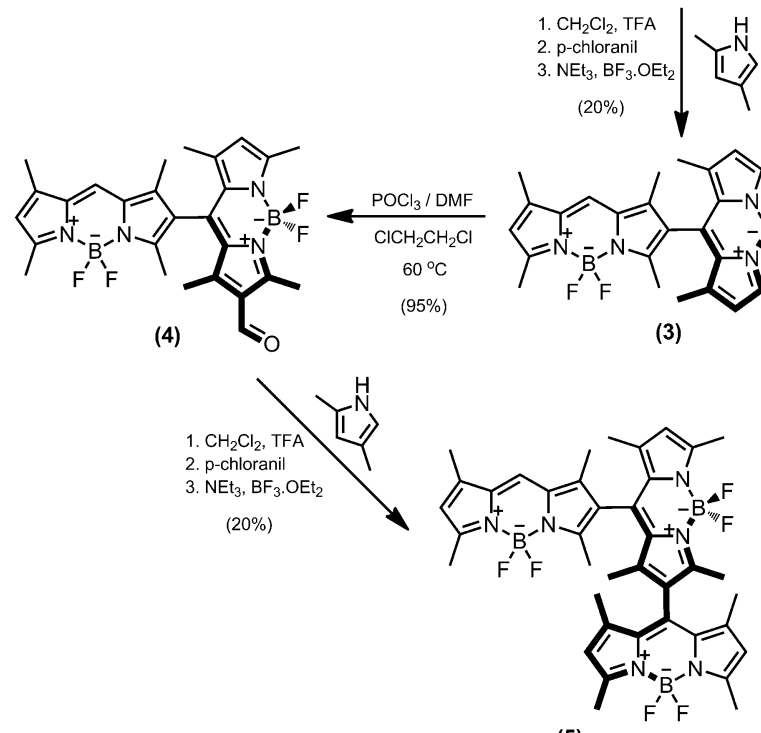

(5)

${ }^{a}$ As expected, $\mathbf{4}$ and $\mathbf{5}$ are produced as racemates. For both $\mathbf{4}$ and $\mathbf{5}$, $(R)$ enantiomers are depicted.

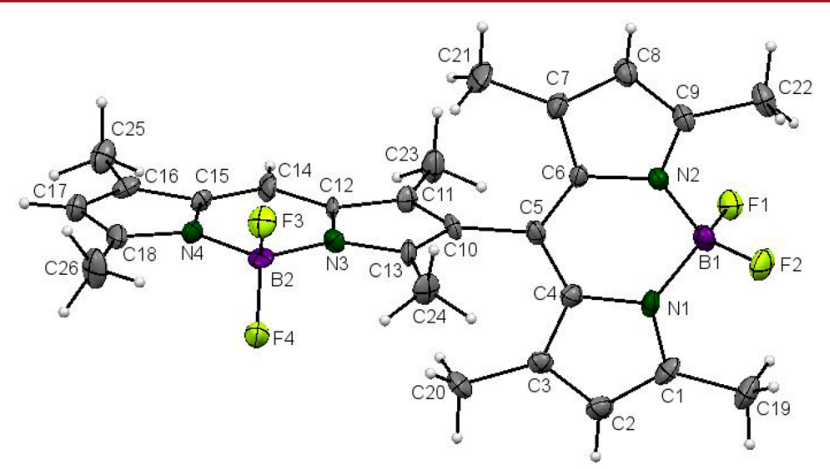

Figure 1. Single crystal X-ray diffraction structure of the orthogonal dimer 3 (50\% probability level). ${ }^{5 a}$ Dihedral angle between the two BODIPY cores is $89.4^{\circ}$.

Analytical and preparative HPLC separations of racemic mixtures of compounds $\mathbf{4}$ and $\mathbf{5}$ were performed using cellulose based Chiralcel-OD columns. For analytical and preparative resolutions, a racemic mixture of the compounds was dissolved in an isocratic eluent of isopropyl alcohol or ethanol/heptane, filtered, and injected to the column.

HPLC chromatograms are shown in Figure 2. Racemic compound 4 yielded easily resolvable peaks under these conditions, but the resolution for $\mathbf{5}$ was somewhat more challenging. Separated enantiomers were checked for their mass/NMR/optical spectra (see Supporting Information) and were found to be identical as expected.

Circular dichroism data (Figures 3 and 4) clearly demonstrate successful separation of the two enantiomers. While the racemic mixture 4 resulted in an essentially flat line indicative of achirality, enantiomer $4 a$ and the enantiomer $4 b$

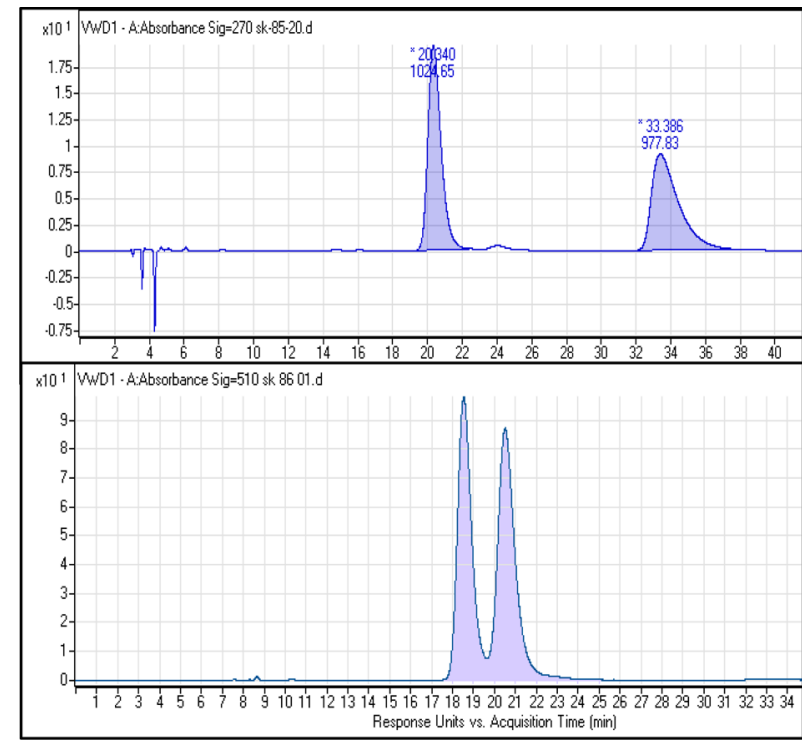

Figure 2. HPLC separation of compound 4 to $\mathbf{4 a}(20.3 \mathrm{~min})$ and $\mathbf{4 b}$ (33.4 min) (95\%/5\%, heptane/IPA, detection @270 nm) (top) and compound $\mathbf{5}$ to $\mathbf{5 a}(18.5 \mathrm{~min})$ and $\mathbf{5 b}(20.6 \mathrm{~min})(98 \% / 2 \%$, heptane/ ethanol, detection @510 nm) (bottom).

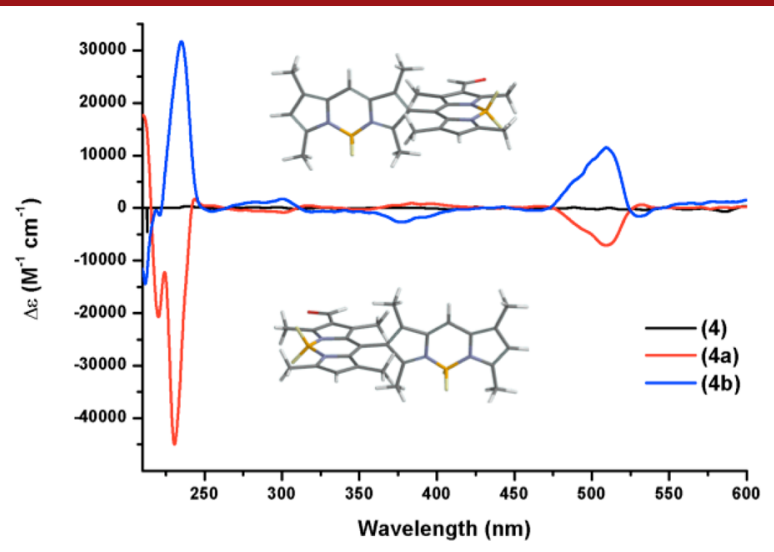

Figure 3. Circular dichroism spectra of racemic mixture 4 and the two enantiomers following resolution using Chiralcel-OD columns via preparative HPLC. The structures shown on the figure are the energy minimized structures (Supporting Information), and the assignment is arbitrary.

show the mirror image spectra. The same is true for $\mathbf{5 , 5 a}$, and $\mathbf{5 b}$. The peaks in the visible region are related to the sharp $S_{0}-$ $\mathrm{S}_{1}$ transition of the BODIPY core.

Compound 4 has a major absorption band in the visible region $\left(\lambda_{\max }=505 \mathrm{~nm}, \varepsilon=78000 \mathrm{M}^{-1} \mathrm{~cm}^{-1}\right)$. Only weak fluorescence emission (quantum yield $<1 \%$ ) is observed with a peak at $520 \mathrm{~nm}$. The trimer, on the other hand, has a stronger absorption at $514 \mathrm{~nm}\left(\varepsilon=162000 \mathrm{M}^{-1} \mathrm{~cm}^{-1)}\right.$. This compound also has a low quantum yield of emission (quantum yield $<1 \%$ ) (Figure 5, Table 1).

The low quantum yields are to be expected based on our earlier work ${ }^{5 \mathrm{a}, \mathrm{b}}$ suggesting unusual excited state configurations leading to fast intersystem crossing. In summary, we present the first example of atropisomeric BODIPY derivatives with persistent chirality due to multiple methyl group clashes. The orthogonally linked BODIPY compounds have been demonstrated to have interesting photophysical properties, but now, we show that they can be isolated as atropisomeric chiral 


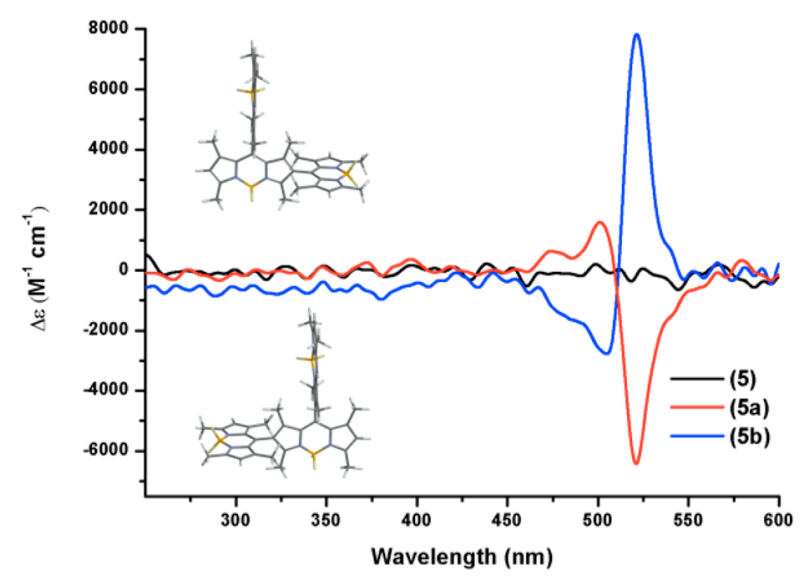

Figure 4. Circular dichroism spectra of racemic mixture 5 and the two enantiomers following resolution using Chiralcel-OD columns via preparative HPLC. The structures shown on the figure are the energy minimized structures (Supporting Information), and the assignment is arbitrary.

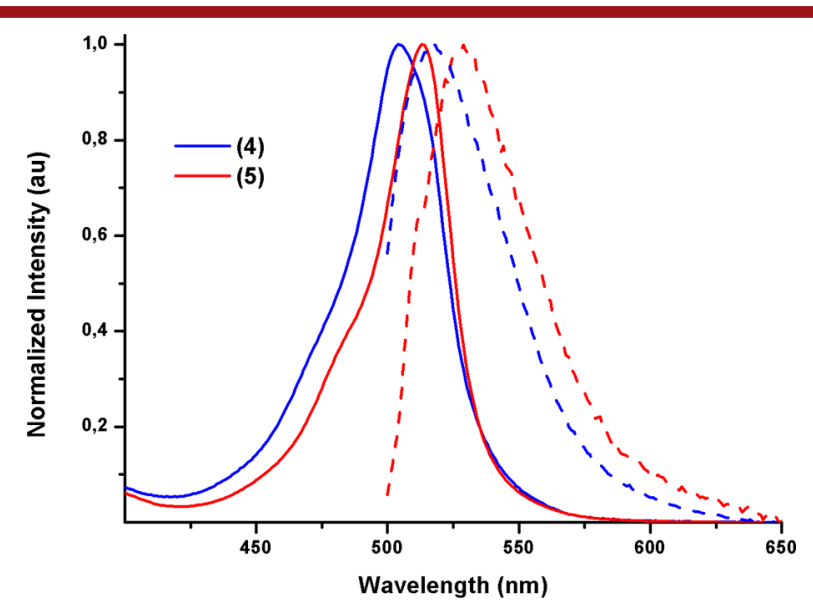

Figure 5. Electronic absorption (solid line) and emission (dashed line) spectra of compounds $\mathbf{4}$ and $\mathbf{5}$. Emission quantum yield is very low.

Table 1. Photophysical Characterization of Compounds 4 and 5

$\begin{array}{cccccc}\text { dye } & \lambda_{\text {abs }}{ }^{a} / \mathrm{nm} & \varepsilon_{\max } / \mathrm{M}^{-1} \mathrm{~cm}^{-1} & \lambda_{\text {ems }}{ }^{a} / \mathrm{nm} & \Phi_{\mathrm{f}}{ }^{b} & \tau_{\mathrm{f}}^{a} / \mathrm{ns} \\ \mathbf{4} & 505 & 78000 & 520 & 0.0078 & 3.14 \\ \mathbf{5} & 514 & 162000 & 528 & 0.0075 & 3.72\end{array}$

${ }^{a}$ Data acquired in $\mathrm{CH}_{2} \mathrm{Cl}_{2} \cdot{ }^{b}$ In reference to fluorescein in $0.1 \mathrm{M}$ $\mathrm{NaOH}$ solution, excited at $495 \mathrm{~nm}$.

compounds. Their large extinction coefficients and large anisotropy factors $\left(g>5 \times 10^{-3}\right)$ would mean that similar compounds may find practical applications as chiroptical fluorogenic/chromogenic sensors, and as highly selective chiral photosensitizers in a therapeutic context, among other potential fields. Our work along that line is in progress.

\section{ASSOCIATED CONTENT}

\section{S Supporting Information}

Methods, experimental procedures, additional spectral data. This material is available free of charge via the Internet at http://pubs.acs.org.

\section{AUTHOR INFORMATION}

\section{Corresponding Author}

*E-mail: eua@fen.bilkent.edu.tr.

\section{Author Contributions}

$\S_{\text {}}$ These authors contributed equally.

\section{Notes}

The authors declare no competing financial interest.

\section{ACKNOWLEDGMENTS}

The authors gratefully acknowledge partial support from TUBITAK. We also thank Mr. Bora Bilgic (Roketsan Inc. Ankara, Turkey) for his contribution to the graphical abstract.

\section{REFERENCES}

(1) (a) Ziessel, R.; Ulrich, G.; Harriman, A. New J. Chem. 2007, 31, 496. (b) Loudet, A.; Burgess, K. Chem. Rev. 2007, 107, 4891. (c) Ulrich, G.; Ziessel, R.; Harriman, A. Angew. Chem., Int. Ed. 2008, 47, 1184.

(2) (a) Sunahara, H.; Urano, Y.; Kojima, H.; Nagano, T. J. Am. Chem. Soc. 2007, 129, 5597. (b) Yin, S. C.; Leen, V.; Van Snick, S.; Boens, N.; Dehaen, W. Chem. Commun. 2010, 46, 6329. (c) Niu, S.; Massif, C.; Ulrich, G.; Renard, P.; Romieu, A.; Ziessel, R. Chem.-Eur. J. 2012, 18, 7229. (d) Isik, M.; Ozdemir, T.; Simsek-Turan, I.; Kolemen, S.; Akkaya, E. U. Org. Lett. 2013, 15, 216. (e) Rurack, K.; Kollmansberger, M.; Resch-Genger, U.; Daub, J. J. Am. Chem. Soc. 2000, 122, 968. (f) Erbas-Cakmak, S.; Bozdemir, O. A.; Cakmak, Y.; Akkaya, E. U. Chem. Sci. 2013, 4, 858. (g) Kolemen, S.; Bozdemir, O. A.; Cakmak, Y.; Barin, G.; Ertan-Ela, S.; Marszalek, M.; Yum, J. H.; Zakeeruddin, S. M.; Nazeeruddin, M. K.; Grätzel, M.; Akkaya, E. U. Chem. Sci. 2011, 2, 949. (h) Baglan, M.; Ozturk, S.; Gur, B.; Meral, K.; Bozkaya, U.; Bozdemir, O. A.; Atilgan, S. RSC Adv. 2013, 3, 15866. (i) Zhao, W. L.; Carreira, E. M. Angew. Chem., Int. Ed. 2005, 44, 1677. (j) Mula, S.; Ray, A. K.; Banerjee, M.; Chaudhuri, T.; Dasgupta, K.; Chattopadhyay, S. J. Org. Chem. 2008, 73, 2146. (k) Li, F.; Yang, S. I.; Ciringh, Y. Z.; Seth, J.; Martin, C. H.; Singh, D. L.; Kim, D.; Birge, R. R.; Bocian, D. F.; Holten, D.; Lindsey, J. L. J. Am. Chem. Soc. 1998, 120, 10001. (1) Lu, J.S.; Fu, H.; Zhang, Y.; Jakubek, Z. J.; Tao, Y.; Wang, S. Angew. Chem., Int. Ed. 2011, 50, 11658.

(3) (a) Lim, S. H.; Thivierge, C.; Nowak-Siliwinska, P.; Han, J.; van den Bergh, H.; Wagnieres, G.; Burgess, K.; Lee, H. B. J. Med. Chem. 2010, 53, 2865. (b) Erbas, S.; Gorgulu, A.; Kocakusakogullari, M.; Akkaya, E. U. Chem. Commun. 2009, 4956.

(4) (a) Kamkaew, A.; Lim, S. H.; Lee, H. B.; Kiew, L. V.; Chung, L. Y.; Burgess, K. Chem. Soc. Rev. 2013, 42, 77. (b) Awuah, S. G.; You, Y. RSC Adv. 2012, 2, 11169. (c) Yogo, T.; Urano, Y.; Ishitsuka, F.; Nagano, T. J. Am. Chem. Soc. 2005, 127, 12162. (d) Gallagher, W. M.; Allen, L. T.; O'Shea, C.; Kenna, T.; Hall, M.; Gorman, A.; Killoran, J.; O'Shea, D. F. J. Cancer 2005, 92, 1702. (e) McDonnell, S. O.; Hall, M. J.; Allen, L. T.; Byrne, A.; Gallagher, W. M.; O’Shea, D. F. J. Am. Chem. Soc. 2005, 127, 16360. (f) Ozlem, S.; Akkaya, E. U. J. Am. Chem. Soc. 2009, 131, 48.

(5) (a) Cakmak, Y.; Kolemen, S.; Duman, S.; Dede, Y.; Dolen, Y.; Kilic, B.; Kostereli, Z.; Tatar-Yildirim, L.; Dogan, A. L.; Guc, D.; Akkaya, E. U. Angew. Chem., Int. Ed. 2011, 50, 11937. (b) Duman, S.; Cakmak, Y.; Kolemen, S.; Akkaya, E. U.; Dede, Y. J. Org. Chem. 2012, $77,4516$.

(6) (a) Yorozu, T.; Hayashi, K.; Irie, M. J. Am. Chem. Soc. 1981, 103, 5480. (b) Avnir, D.; Wellner, E.; Ottolenghi, M. J. Am. Chem. Soc. 1989, 111, 2001. (c) Hu, Q.-S.; Pugh, V.; Sabat, M.; Pu, L. J. Org. Chem. 1999, 64, 7528. (d) Gong, L.-Z.; Hu, Q.-S.; Pu, L. J. Org. Chem. 2001, 66, 2358. (e) Lin, J.; Zhang, H.-C.; Pu, L. Org. Lett. 2002, 4, 3297. (f) Takeuchi, M.; Yoda, S.; Imada, T.; Shinkai, S. Tetrahedron 1997, 53, 8335. (g) Liu, H.-L; Peng, Q.; Wu, Y.-D.; Chen, D.; Hou, X.L.; Sabat, M.; Pu, L. Angew. Chem., Int. Ed. 2010, 49, 602. (h) Yu, S.; Pu, L. J. Am. Chem. Soc. 2010, 132, 17698. (i) Pu, L. Chem. Rev. 2004, 
104, 1687. (j) Leung, D.; Kang, S. O.; Anslyn, E. V. Chem. Soc. Rev. 2012, 41, 448.

(7) (a) Beer, G.; Rurack, K.; Daub, J. Chem. Commun. 2001, 1138. (b) Gossauer, A.; Nydegger, F.; Kiss, T.; Sleziak, R.; Stoeckli-Evans, H. J. Am. Chem. Soc. 2004, 126, 1772. (c) Moczar, I.; Huszthy, P.; Maidics, Z.; Kadar, M.; Toth, K. Tetrahedron 2009, 65, 8250. (d) Ikeda, C.; Maruyama, T.; Nabeshima, T. Tetrahedron 2009, 50, 3349. (e) Beer, G.; Niederalt, C.; Grimme, S.; Daub, J. Angew. Chem., Int. Ed. 2000, 39, 3252. (f) Kim, H.; Burghart, A.; Welch, M. B.; Reibenspies, J.; Burgess, K. Chem. Commun. 1999, 1889.

(8) Haefele, A.; Zedde, C.; Retailleau, P.; Ulrich, G.; Ziessel, R. Org. Lett. 2010, 12, 16. 